\title{
Human L-Ficolin (Ficolin-2) and Its Clinical Significance
}

\author{
David C. Kilpatrick ${ }^{1}$ and James D. Chalmers ${ }^{2}$ \\ ${ }^{1}$ Scottish National Blood Transfusion Service, National Science Laboratory, Ellen's Glen Road, Edinburgh EH17 7QT, UK \\ ${ }^{2}$ MRC Centre for Inflammation Research, University of Edinburgh, 47 Little France Crescent, Edinburgh EH16 4TJ, UK
}

Correspondence should be addressed to David C. Kilpatrick, david.kilpatrick@nhs.net

Received 15 September 2011; Accepted 14 November 2011

Academic Editor: Misao Matsushita

Copyright (C) 2012 D. C. Kilpatrick and J. D. Chalmers. This is an open access article distributed under the Creative Commons Attribution License, which permits unrestricted use, distribution, and reproduction in any medium, provided the original work is properly cited.

Human L-ficolin (P35, ficolin-2) is synthesised in the liver and secreted into the bloodstream where it is one of the major pattern recognition molecules of plasma/serum. Like other ficolins, it consists of a collagen-like tail region linked to a fibrinogen-related globular head; a basic triplet subunit arises via a collagen-like triple helix, and this then forms higher multimers (typically a 12-mer, $\mathrm{Mr} 400 \mathrm{~K})$. Unlike other ficolins, it has a complex set of binding sites arranged within an internal cleft enabling it to recognise a variety of molecular patterns including acetylated sugars and certain 1,3- $\beta$-glucans. It is one of the few molecules known to activate the lectin pathway of complement. Recently, some disease association studies (at either the DNA or protein level) have implicated L-ficolin in innate immunity, where it might cooperate with pentraxins and collectins. Emerging lines of evidence point to a role for L-ficolin in respiratory immunity, where its affinity for Pseudomonas aeruginosa could be significant.

\section{Introduction}

1.1. Discovery. Ficolins were first discovered as transforming growth factor $\beta$-binding proteins present in porcine uterus, characterised by the possession of both fibrinogenrelated and collagen-like domains [1]. However, it was the description of P35 as an opsonic, GlcNAc-specific lectin that first indicated that this family could be involved in innate immunity as pattern recognition molecules [2]. A very similar molecule named L- (for liver) ficolin was independently purified from human plasma on GlcNAc-Sepharose [3]. Both resembled two other previously discovered plasma proteins: EBP-37, which bound elastin [4], and hucolin, which bound a corticosteroid derivative [5].

Despite some minor discrepancies in properties, it was clear that the same protein was being isolated on different affinity matrices, and the term L-ficolin (or ficolin-2) is now used for this protein with a rather catholic taste in ligands. In this, as in several other features, it resembles the intensively studied mannan- (or mannose-) binding lectin [6], but by definition a ficolin has a fibrinogen-like domain combined with a collagen-like domain and is therefore not a collectin. (Collectins combine a collagen-like domain with a C-type lectin domain and resemble ficolins and $\mathrm{Clq}$ in tertiary structure.)
1.2. The Ficolin Family. Porcine ficolins consist of two homologous molecules, designated ficolin- $\alpha$ and $-\beta$. Although first discovered in uterine tissue, porcine ficolin- $\alpha$ is more abundant in liver and blood where two isoforms, "little ficolin" (Mr 400 000) and "big ficolin" (Mr 800 000) were described [7]. Ficolin- $\beta$, with around $80 \%$ identity to ficolin$\alpha$, was found to be expressed mainly in neutrophils [8].

A similar situation exists in mice. Ficolin A is present in liver and blood plasma, while ficolin B (60\% identical) is expressed in bone marrow and spleen and is associated with macrophages $[9,10]$.

These findings have prompted the generalisation that ficolins can be classified into soluble serum ficolins and cellbound ficolins whatever the species. This view is supported by a similar dichotomy in the toad, Xenopus laevis [11]. The relationships between ficolins in the above species and others have been reviewed in more detail by Matsushita [12] and by Garred et al. 2010 [13].

1.3. Human Ficolins. Unlike pigs or mice, humans have three ficolins, all of which are present in the bloodstream: Mficolin (monocyte ficolin or ficolin-1); L-ficolin (liver ficolin or ficolin-2); and $\mathrm{H}$-ficolin (Hakata antigen or ficolin-3). $\mathrm{M}$ - and L-ficolin have approximately $80 \%$ identity in amino acid sequence; $\mathrm{H}$-ficolin has only about $50 \%$ identity with 
TABLE 1: The human ficolins.

\begin{tabular}{|c|c|c|c|}
\hline & M-ficolin & L-ficolin & H-ficolin \\
\hline Molecular size (subunit) & $35 \mathrm{~K}$ & $35 \mathrm{~K}$ & $34 \mathrm{~K}$ \\
\hline Molecular size (native) & $900 \mathrm{~K}$ & $420 \mathrm{~K}$ & $610 \mathrm{~K}$ \\
\hline Location & Neutrophils, monocytes $>$ serum & liver; serum & liver; bile; lung; serum \\
\hline Chemical specificity & Acetylated sugars & $\begin{array}{l}\text { acetylated compounds; } \\
\text { LPS; } 1,3-\beta \text {-glucans; } \\
\text { lipoteichoic acids; } \\
\text { elastin; steroids }\end{array}$ & $\begin{array}{c}\text { D-fucose }>\text { GlcNAc; } \\
\text { polysaccharide from } \\
\text { A.viridans }\end{array}$ \\
\hline Microbial specificity & E. coli; S. aureus; S. agalactiae & $\begin{array}{l}\text { S. aureus; S. pneumoniae; } \\
\text { S. typhimurium; E. coli; } \\
\text { P. aeruginosa; M. bovis; } \\
\text { G. lamblia; T. cruzi; } \\
\quad \text { A. fumigatus, }\end{array}$ & A. viridans; T. cruzi \\
\hline Complement activation & Yes & Yes & Yes \\
\hline Opsonic activity & $?$ & Yes & $?$ \\
\hline Collagenase sensitivity & Yes & Yes & No \\
\hline
\end{tabular}

the other two. M-ficolin, predominantly found in monocytes and granulocytes, is the homologue of murine ficolin-B and porcine ficolin- $\beta$; L-ficolin is the homologue of murine ficolin-A and porcine ficolin- $\alpha[12]$.

The third human ficolin, the Hakata antigen originally identified and defined by autoantibodies present in a small minority of lupus patients, is synthesised in both liver (secreted into bile as well as blood) and lung (and secreted into the bronchi). It is the most abundant plasma ficolin and the most potent at activating complement in vitro $[14,15]$.

A comparison of the properties of the ficolins is summarised in Table 1. All three have the ability to activate the lectin pathway of complement, an activity known to be shared with just two collectins, mannan-binding lectin (MBL) and CL-L1 [16, 17]. All three ficolins seem to recognise acetylated sugars like GlcNAc to some degree. Lficolin (like $\mathrm{MBL}$ ) appears to be a major pattern recognition molecule in human plasma [18]. It has a uniquely complex set of binding sites, potentially conferring the ability to recognise and interact with a wide range of microorganisms [19]. Recently, L-ficolin has been the subject of several disease association studies, providing evidence that L-ficolin complements $\mathrm{MBL}$ as an important component of innate immunity in the circulation. The structure, properties and function(s) of L-ficolin form the remainder of this paper.

\section{Genetics}

The human L-ficolin gene (FCN2) has been localised to chromosome 9 (9q34) [20], like the M-ficolin gene but in contrast to the $\mathrm{H}$-ficolin gene located on chromosome 1. The L-ficolin gene has eight exons (Figure 1). The first exon encodes a signal sequence and the first nine N-terminal residues. Exons 2 and 3 encode a collagen-like region similar to that found in collectins. The fourth exon encodes a link or connecting region. Exons five to eight encode a domain similar in structure to that of the C-terminal portion of the human fibrinogen $\beta$ and $\gamma$ chains that is characterized by the conservation of 24 mainly hydrophobic amino acid residues.
The FCN2 gene is undoubtedly polymorphic. Hummelshoj et al. [21] first described 5 polymorphisms in the promotor region and 9 in the structural gene from a Danish population. Compatible results were reported by Herpers et al. [22], describing 10 single nucleotide polymorphisms in 1888 Dutch blood donors. A later study compared five different ethnic groups; some ethnic-specific polymorphisms were noted, but most were found in all populations [23].

Considerable linkage disequilibrium exists between pairs of promoter and structural gene dimorphisms, complicating the investigation of the relationship between allele expression and protein concentration, but such relationships certainly exist. High concentrations appear to be associated with the variant (minority) nucleotide at promoter position-4, while low concentrations are associated with the variant allele at position 6424 on exon $8[24,25]$. It is perhaps surprising, and certainly confusing, that the latter mutation is also associated with an increased lectin activity (GlcNAc binding). L-ficolin has several independent activities, however, associated with a variety of binding sites (see below), and it is unknown if other activities are affected.

The single nucleotide polymorphisms implicated in influencing protein concentration in one or more studies are listed in Table 2. It is clear however that those mutations have a very modest influence on average L-ficolin values, each being associated with large and overlapping ranges [25]. Although circulating L-ficolin levels appear to be reasonably stable in healthy individuals, it remains to be established if nongenetic influences may have as great or greater an effect than the FCN2 genotype. For example, we found that patients treated for haematological malignancies had significantly lower median serum L-ficolin compared with healthy controls [26]. Moreover, when studying babies with sepsis, we have found large differences in some individuals with time (unpublished).

Most individuals possess one or two of the most common five haplotypes, and Munthe-Fog et al. [25] have helpfully stratified serum L-ficolin concentration according to those haplotypes. From this analysis, it is apparent that FCN2 

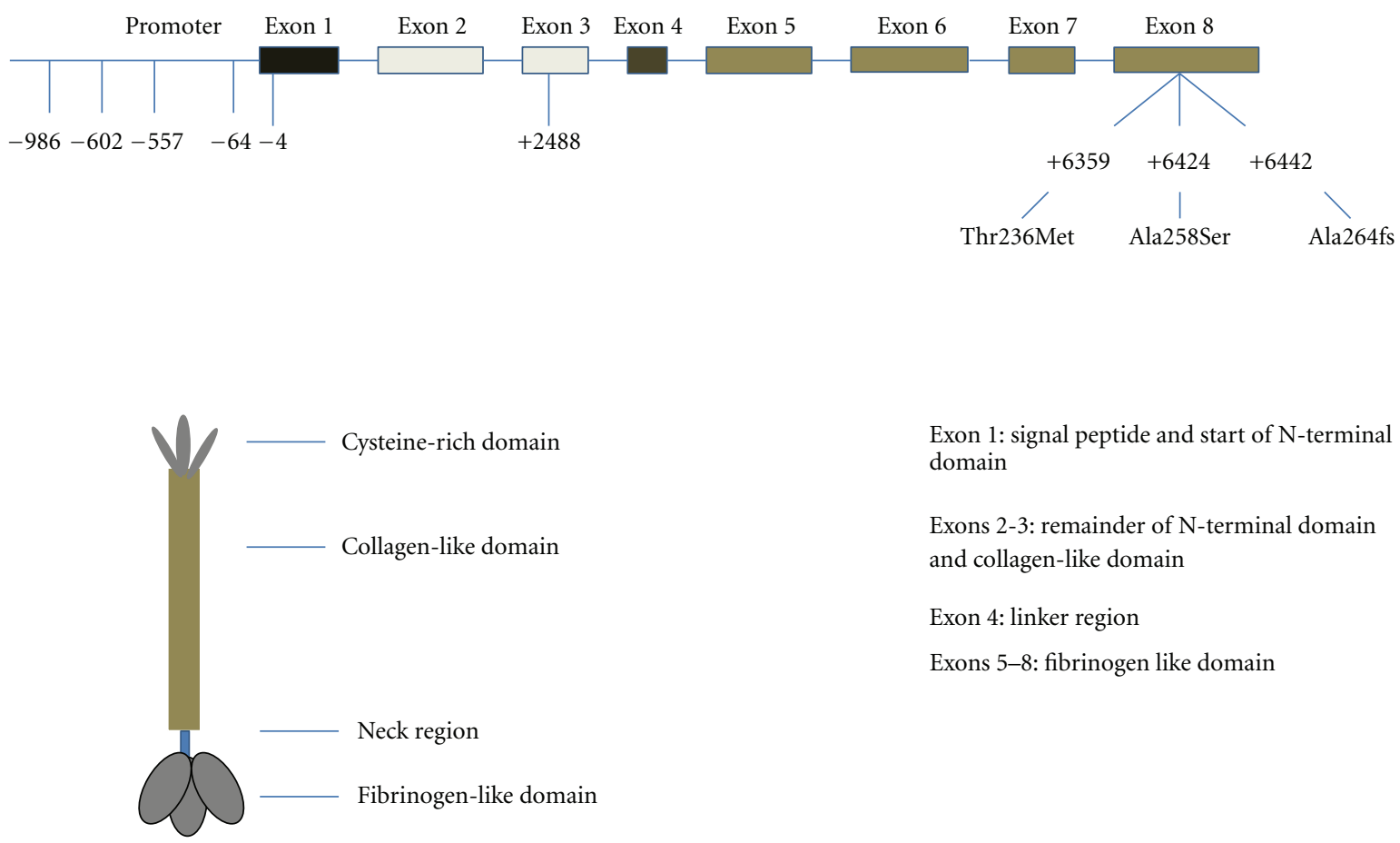

\author{
Exon 1: signal peptide and start of $\mathrm{N}$-terminal \\ domain \\ Exons 2-3: remainder of $\mathrm{N}$-terminal domain \\ and collagen-like domain \\ Exon 4: linker region \\ Exons 5-8: fibrinogen like domain
}

FIGURE 1: The human FCN2 gene. The positions of the major single nucleotide polymorphisms are shown. The mutation at +6442 leads to a deletion ( $\mathrm{fs}=$ frameshift mutation).

TABLe 2: Potentially important polymorphisms in the FCN2 gene.

\begin{tabular}{lccc}
\hline SNP no. & $\begin{array}{c}\text { Region and } \\
\text { position }\end{array}$ & $\begin{array}{c}\text { Base } \\
\text { substitution }\end{array}$ & $\begin{array}{c}\text { Amino acid } \\
\text { substitution }\end{array}$ \\
\hline rs3124952 & promoter -986 & $\mathrm{~A}>\mathrm{G}$ & - \\
rs3124953 & promoter -602 & $\mathrm{G}>\mathrm{A}$ & - \\
rs3811140 & promoter -557 & $\mathrm{~A}>\mathrm{G}$ & - \\
rs28969369 & promoter -64 & $\mathrm{~A}>\mathrm{C}$ & - \\
rs17514136 & promoter -4 & $\mathrm{~A}>\mathrm{G}$ & - \\
rs17549193 & exon $8+6359$ & $\mathrm{C}>\mathrm{T}$ & Thr236Met \\
rs7851696 & exon $8+6424$ & $\mathrm{G}>\mathrm{T}$ & Ala258Ser \\
\hline
\end{tabular}

genotype has little value in predicting protein concentration in individuals. It has been suggested that the huge difference in MBL concentration in general between groups with different MBL2 genotypes is woefully inadequate for predicting serum MBL levels in individuals and that using that approach is unreliable for inferring differences in disease cohorts [27]. That limitation is even more true of FCN2 genotyping, although immunogenetic studies may provide interesting additional information to L-ficolin protein measurement.

\section{Structure}

The primary structure is composed of 288 amino acids forming a gene product of apparent Mr 35000 after glycosylation [2]. A short N-terminal region implicated in multimer formation is followed by a series of 19 (Gly-X-Y) repeats forming the collagen-like region or domain. This is attached via a short linking sequence to a large globular domain with a distinctive fold, homologous to the C-terminal domains found in fibrinogen chains. This fibrinogen-like domain occurs in several apparently unrelated proteins, including tenascins, the acetylated sugar-binding tachylectins from a horseshoe crab (Tachypleus tridentatus) and the sialic acidbinding lectin from the slug, Limax flavus [28].

The combination of fibrinogen-like domain and collagen-like region in L-ficolin (and other ficolins) permits the gene product to form a basic subunit consisting a triple helical tail and a trio of globular heads. This 3-dimensional structure is often likened to a bowl of tulips and resembles the shape of the complement component $\mathrm{Clq}$ and the collectin family despite those other molecules not having primary sequence homology with ficolins or with each other. The triplet subunits can then associate to form higher multimers (Figure 2). The major form in plasma is believed to be a tetramer of subunits (12-mer) with an apparent $\mathrm{Mr}$ of approximately $400000[10,29]$.

L-ficolin uniquely possesses a complex set of binding sites constituting a recognition surface that can detect various acetylated structures and neutral sugars in the context of extended polysaccharides. This conclusion is based on studies of its trimeric recombinant recognition domains solved by X-ray crystallography $[19,30]$. There is an outer binding site ( $\mathrm{S} 1$ ) close to the only calcium binding site. This could be considered the ancestral binding site, as it is homologous to that of the horseshoe crab tachylectin $5 \mathrm{~A}$ as well as that found in human $\mathrm{H}$ - and $\mathrm{M}$-ficolins. Surprisingly, $\mathrm{S} 1$ is not responsible for recognition of acetylated sugars unlike its counterpart in tachylectin 5A. Instead, L-ficolin 


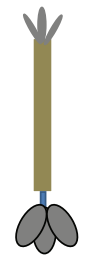

Subunit

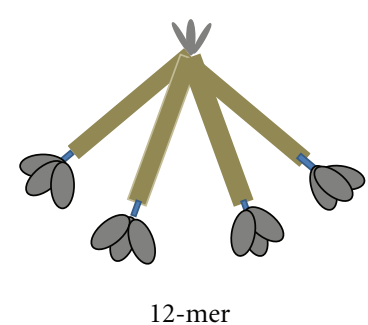

12-mer

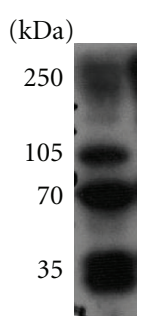

FIGURE 2: L-ficolin structure. The glycosylated gene product of $\mathrm{Mr}$ $35 \mathrm{~K}$ forms a basic triplet subunit. The subunit can form higher multimers, of which the 12 -mer $(4 \times 3)$ is thought to be the most abundant in serum. The inset (right) shows a typical western blot after electrophoresis of L-ficolin under nonreducing conditions.

possesses three inner binding sites (S2, S3, S4) that are located on both sides of a cleft between the upper parts of the protomers. It is S3 that is mainly responsible for binding acetylated structures and also binds 1,3 - $\beta$-glucans with assistance from the minor site, S4. The innermost S2 has affinity for galactose. The L-ficolin recognition groove with its contiguous subsites (S2-S4) is reminiscent of the peptidoglycan binding proteins of invertebrates [19].

The ficolins, collectins, and complement component C1q all have a similar 3-dimensional shape suited to function as multivalent recognition molecules with increased affinity for ligands achieved by multiple protein-oligosaccharide interactions. It is noteworthy that L-ficolin possesses a semiopen structure intermediate between the compact assembly of $\mathrm{Clq}$ and the wide open arrangement of MBL which has little interaction between the lectin domains and a buried surface $8 \%$ the size of that of C1q [19].

The collagen-like region is responsible for the formation of the helical tails of the molecule and also for functional signalling. In particular, the lysine-57 residue is a key component of the binding site for MBL-associated serine proteases and also for calreticulin, a putative complement/collectin/ficolin receptor on phagocytes [31].

\section{Biological Properties}

4.1. Biochemical Specificity. L-ficolin was reported to bind to mannan, mannan-Sepharose, and GlcNAc-BSA in a calciumdependent manner [2], whereas other workers described calcium-independent binding to GlcNAc-Sepharose and elution with GlcNAc [3]. L-ficolin also bound to $\mathrm{CNBr}$ activated (but underivatized) Sepharose blocked with Tris. Since L-ficolin did not bind to mannan coupled to "Emphase" (a polyacrylamide derivative) [32], it seems likely the affinity chromatography was achieved with Sepharose (i.e., polygalactose) not mannan; this interaction was possibly mediated by binding site $\mathrm{S} 2$. The inconsistency regarding calcium is to some extent explained by the observation that L-ficolin bound to GlcNAc-Sepharose or CysNAc-Sepharose beads not only in the presence of calcium but also in the absence of calcium at high $\mathrm{NaCl}$ concentrations [33]. Given that X-ray crystallography has shown that the ancestral (S1) calcium-associated binding site does not bind galactose or acetylated sugars, it appears that the other binding sites are influenced indirectly by their ionic environment.

It is clear that L-ficolin binds not just to acetylated sugars but also to nonsaccharide acetylated compounds [33]. Nevertheless, glycan array studies have established that Lficolin does not bind to most acetylated oligosaccharides found on mammalian glycoconjugates [34]. Rather, L-ficolin has complex recognition requirements and binding probably requires the presence of two or more acetylated sugar groups presented in an appropriate conformation. In another glycan array study, L-ficolin preferentially recognised disulphated $\mathrm{N}$-acetyllactosamine and tri- and tetrasaccharides containing terminal galactose or $\mathrm{N}$-acetylglucosamine and binding was sensitive to the orientation of the bond between $\mathrm{N}$ acetyllactosamine and the adjacent saccharide [35].

L-ficolin is the major 1,3 - $\beta$-glucan-binding protein in human plasma [18] and can bind to lipoteichoic acid [36]. Potentially, therefore, L-ficolin could bind to a wide variety of fungi and Gram-positive bacteria. L-ficolin recognises and binds to the viral envelope glycoproteins (E1 and E2) of the hepatitis $\mathrm{C}$ virus and triggers the lectin pathway of complement by binding to a virally infected human hepatoma cell line [37].

L-ficolin also appears to bind human DNA, suggesting a mechanism for attaching to apoptotic or necrotic autologous cells and thus promoting the removal of dead and moribund cells and tissues [38]. It has already been mentioned that L-ficolin can bind to a protein, elastin [4], and a lipid [5]. Most significantly, it can bind to the pentraxins, C-reactive protein [39], pentraxin 3 (PTX3) [40], and serum amyloid P component (J. D. Chalmers, unpublished).

4.2. Microbial Specificity. L-ficolin has been found to bind to the Gram-negative bacteria, Salmonella typhimurium (Ra strain) [2], Escherichia coli [41], and Pseudomonas aeruginosa [42], as well as the Gram-positive species, (capsulated) Staphylococcus aureus and streptococci including the pneumococcus $[33,43,44]$. All interactions were partially sensitive to GlcNAc. L-ficolin binding to the intracellular bacterium Mycobacterium bovis has also been reported [45]. Additionally, binding to Haemophilus influenzae and Moraxella catarrhalis has been observed (J. D. Chalmers, unpublished).

Binding of L-ficolin to the protozoan causing Chagas' disease, Trypanosoma cruzi, has been demonstrated [46] and to the intestinal protozoan Giardia lamblia [47]. It also binds the opportunistic fungal pathogen, Aspergillus fumigatus [40]. This last interaction can be partially inhibited by GlcNAc or Curdlan (a $\beta$-1,3-glucose polymer).

The L-ficolin-mediated response to A. fumigatus is enhanced by calcium-independent binding to PTX3 [40]. Similar synergy was observed between L-ficolin and Creactive protein in response to $P$. aeruginosa [42]. These appear to be impressive examples of how L-ficolin can combine with pentraxins to amplify antimicrobial recognition and effector mechanisms.

4.3. Complement Activation. L-ficolin is one of the few molecules known to activate the lectin pathway of complement 
activation [48]. This arises after forming a complex with MBL-associated serine proteases (MASP)-1, -2 , and -3 , of which MASP-2 is crucial for complement activation. MASP2 binding takes place at a site on the collagen-like region [31]. L-ficolin-MASP-2 interaction leads to activation of the latter, enabling it to cleave complement components $\mathrm{C} 2$ and $\mathrm{C} 4$ in a manner similar to the $\mathrm{Clq}, \mathrm{r}, \mathrm{s}$ complex of the classical pathway initiated by antigen-antibody formation. The roles of MASP- 1 and its alternatively spliced gene product MASP-3 are less clear, but evidence is accumulating that MASP-1 may link complement to the coagulation system [49-53] as well as collaborating with MASP-2 in the generation of the C3 convertase $[54,55]$. MASP-3 is primarily found complexed to $\mathrm{H}$-ficolin and appears to regulate complement activation mediated by the latter [56].

The other activators of MASP-2 and hence the lectin pathway are the other human ficolins ( $\mathrm{M}$ - and $\mathrm{H}$-ficolin) and the collectins, MBL and CL-11/CL-K1 [16, 17]. In so far as they have been directly compared, $\mathrm{H}$-ficolin emerged as the most potent complement activator, at least as measured in vitro by a particular C4 deposition assay [15]. L-ficolin and MBL were similar, but had only half the complement activation capacity of $\mathrm{H}$-ficolin.

Unsurprisingly, L-ficolin has been shown to possess opsonic activity by enhancing phagocytosis of Salmonella by human neutrophils [2]. It can also promote the phagocytosis of Pseudomonas aeruginosa [42] and Streptococcus pneumoniae (J. D. Chalmers, unpublished). Although such opsonisation may be mediated by complement activation, it has also been suggested that L-ficolin can opsonise bacteria by binding calreticulin on phagocytes via its collagen-like domain [31].

L-ficolin can cooperate with pentraxins to opsonise bacteria and initiate the lectin pathway, as was mentioned earlier.

Two reports support the view that L-ficolin can opsonise autologous dead or dying cells and cellular debris [38, 57]. Kuraya et al. [57] concluded that L-ficolin binds to apoptotic cells and activates complement via the lectin pathway. Jensen et al. [38], however, observed binding to necrotic but not apoptotic cells, and only at supraphysiological concentrations of $\geq 20 \mu \mathrm{g} / \mathrm{mL}$. High concentrations of L-ficolin also promoted the uptake of necrotic Jurkat cells by monocytederived macrophages in a phagocytosis assay [38]. Many molecules have been described as binding to apoptotic cells, however, and we have no idea of their relative physiological significance in vivo.

\section{L-Ficolin in Health and Disease}

5.1. L-Ficolin in Healthy Subjects. In healthy adult individuals, the distribution of serum L-ficolin is perfectly Gaussian, so the mean and median are exactly the same. That value has generally been reported to be between 3 and $4 \mu \mathrm{g} / \mathrm{mL}$ [58] although more recently it has been determined at $5.4 \mu \mathrm{g} / \mathrm{mL}$ [25]. A complicating consideration is that purified L-ficolin is very labile (unlike in serum); if anything other than a recently isolated preparation is used as a standard, the values obtained from the calibration curve will be higher than the true values. There is also scope for discrepancy between immunoassayed protein and a measurement based on activity. However, in general, we have found broadly similar values to be obtained with either acetylated BSA or anti-L-ficolin antibody (clone GN4) as solid-phase capture agent combined with the same labelled detection antibody (clone GN5).

Most normal values fall within the range 1000 to $6000 \mathrm{ng} / \mathrm{mL}$, although occasionally much higher values are detected. No value much below $1000 \mathrm{ng} / \mathrm{mL}$ has been detected in a healthy adult; therefore, absolute L-ficolin deficiency has not been shown to exist. From genetic studies [21], a homozygous frameshift mutation in exon 8 (rs28357091; Ala264fs; FCN2-D) would be expected to give total deficiency, but this has not yet been found.

Normal values are generally lower in antenatal (cord blood) sera [3, 59-61] and correlate with gestational age, at least until shortly before term [60]. Only one study has investigated serum L-ficolin throughout life [61]. The highest values were found between 1 and 4 years of life (median $11300 \mathrm{ng} / \mathrm{mL}$ ), then dropped during later childhood (4-16 years, median $8660 \mathrm{ng} / \mathrm{mL}$ ) before reaching a stable adult level (median 3370) after 16 years of age. Although Sallenbach et al.'s values [61] were in good agreement with our and others' adult data and reasonably close agreement for antenatal data, their elevated values for later childhood were at variance with our finding of similar-to-adult values for such children [62].

Although no absolute deficiency of L-ficolin has yet been discovered, it seems possible that relative deficiency ("insufficiency") defined by low serum L-ficolin \pm immunogenetics could contribute to disease susceptibility. Unfortunately, the disease process itself (or treatment) might affect circulating L-ficolin, as has been found for patients with haematological malignancies [26], preeclampsia [63], and sepsis (D. C. Kilpatrick, unpublished).

5.2. General Infections. L-ficolin insufficiency was associated with perinatal infections in preterm Polish babies [60]. In a cohort of over 1800 consecutive deliveries, the rate of perinatal infections in babies with cord blood L-ficolin $<1000 \mathrm{ng} / \mathrm{mL}$ (the lowest 9\%) was twice that of babies with higher concentrations $(13.7 \%$ versus $7.7 \%$; $P<0.01)$. This relationship was not independent of gestational age and birthweight, but suggests that L-ficolin insufficiency could be one of several factors that contribute to the adverse consequences of prematurity and low birthweight [60].

Schlapback et al. [64], however, found no significant relationship between low cord blood L-ficolin and sepsis in 47 premature infants. This was despite finding significant relationships between low $\mathrm{H}$-ficolin and Grampositive sepsis and between low MBL and Gram-negative sepsis. Incidentally, that study did confirm correlations between L-ficolin concentration and both gestational age and birthweight. It is possible that study was underpowered for L-ficolin: for Gram-negative sepsis, 47\% (7/15) of the patients had low $(<1000 \mathrm{ng} / \mathrm{mL})$ L-ficolin compared with $23 \%(22 / 94)$ of infection-free, matched controls $(P<0.07)$ [64]. 
Uraemic patients have an increased susceptibility to infection, and peritonitis is a common complication in patients on continuous ambulatory peritoneal dialysis (CAPD). The $+6359 \mathrm{C}>\mathrm{T}$ variant in the FCN2 gene, causing a Thr Met alteration and a concomitant decrease in lectin activity, was found to be commoner in CAPD patients with a history of staphylococcal peritonitis compared with CAPD patients without such a history [65]. In the former, exit site Staphylococcus aureus was also more prevalent [65].

Another clinical context of interest is that of chemotherapy \pm transplantation. MBL has been intensively studied in this context with wildly differing results $[66,67]$. In our series of haematological malignancy patients who were rendered severely neutropenic, entirely negative results were obtained for both L-ficolin and H-ficolin [26].

However, the situation appears to be very different in the context of liver transplantation, where the recipient assumes the phenotype of the donor. The variant FCN2 +6359 allele was associated with a doubling of the bacterial infection risk within the first year following transplant, and the risk was enhanced by coinheritance of MBL2 variant alleles [68]. Patients with one or more lectin pathway genetic variants and infection had a much increased mortality rate which was highly statistically significant [68]. As well as those bacterial infections causing sepsis and pneumonia, the normal (high lectin activity) FCN2 +6359 was associated with protection from cytomegalovirus after liver transplantation [69]. Again, the combination of FCN2 and MBL2 risk alleles conferred a particularly high degree of susceptibility.

5.3. Respiratory Infections. There is a strong theoretical basis to believe L-ficolin may be important in respiratory infections. As discussed previously, L-ficolin binds to and opsonises a wide variety of important respiratory pathogens (including capsulated S. pneumoniae, S. aureus, P. aeruginosa, $H$. influenzae and others). L-ficolin, like MBL, has been found in the inflamed lung (induced sputum and bronchoalveolar lavage fluid) in concentrations sufficient to cause complement activation (J. D. Chalmers, unpublished).

In perhaps the first disease association study involving L-ficolin, an association between L-ficolin insufficiency and recurrent respiratory infections in children was reported. This relationship was particularly marked for patients with coexisting allergic disorders (mostly rhinitis and/or asthma with high IgE) [70]. This preliminary observation prompted a fresh, prospective study on children aged 1 to 16 years (mean 8.9) to confirm or refute the previous retrospective findings and to distinguish between infection and allergy [62]. L-ficolin insufficiency was indeed significantly associated with asthma and/or allergic rhinitis in the context of recurrent respiratory infections, but not with those allergic disorders in the absence of infection or with recurrent respiratory infections in the absence of allergy [62]. The reason for this relationship is not clear, but it is possible that L-ficolin confers some protection from microorganisms that exacerbate allergic inflammation in the lung.

Another research group examined FCN2 variants in a birth cohort followed up for 4 years. Analysis based on constructed haplotypes yielded no relationship with recurrent respiratory infection. No serum L-ficolin measurements were made [71].

Similarly negative immunogenetic results were obtained in a study of invasive pneumococcal disease [72], but again no serum L-ficolin data were obtained.

There was a clear association between low serum Lficolin and idiopathic bronchiectasis [73]. This has since been confirmed in a much larger series, and there is evidence to suggest the basis could lie in protection from colonisation with Pseudomonas aeruginosa [74]. Certainly, low serum L-ficolin in those patients identifies a clinical phenotype associated with more severe disease and therefore with poorer quality of life.

5.4. Other Infectious Diseases. The distribution of FCN2 haplotypes in leprosy patients differed significantly from healthy controls [75]. The authors interpreted their findings as an indication that normal (relatively high) L-ficolin concentrations protect against $M$. leprae infections, but serum L-ficolin was not actually measured.

A comparison of mild and severe Plasmodium falciparum malaria revealed that serum L-ficolin concentration is highest during acute severe disease, but this difference was not reflected in the distribution of the FCN2 haplotypes [76].

In contrast, the distribution of FCN2 haplotypes was altered in cutaneous leishmaniasis patients when compared with healthy controls [77]. Haplotypes expected to confer normal concentrations of L-ficolin were commoner in the controls, but again serum L-ficolin was not actually measured.

5.5. Pregnancy Disorders. A small proportion of women who had experienced recurrent miscarriage had serum L-ficolin values below the lower limit of normal [59]. These patients were sampled at a single point in time, and a longitudinal study would be required to determine if those low values were stable. It would also be instructive to learn if and how L-ficolin varied during pregnancy in such patients.

According to Wang and coworkers [63], serum L-ficolin increases several-fold during normal pregnancy, although it is not clear whether a direct comparison was made between pregnant and nonpregnant subjects. (Moreover, van de Geijn et al. [78] reported that serum L-ficolin was not influenced by pregnancy.) Certainly, Wang et al. found L-ficolin levels to be significantly lower in preeclamptic pregnancies compared with uncomplicated pregnancies of similar gestational age. Postnatal placentae from preeclamptic pregnancies contained higher concentrations of L-ficolin in lysates, and more intense immunohistochemical staining was observed in syncytiotrophoblast. The co-expression of L-ficolin and Ras protein in preeclamptic syncytiotrophoblast was noted. The authors interpret those observations as evidence of consumption of L-ficolin by apoptotic trophoblast causing depletion in the circulation.

5.6. Miscellaneous Disorders. The distribution of FCN2 variants was found to be altered in poststreptococcal disease [79]. A haplotype associated with low levels of L-ficolin 
TABLE 3: Some disease associations of L-ficolin insufficiency.

\begin{tabular}{lcc}
\hline Disease & Associated with & Reference \\
\hline $\begin{array}{l}\text { Perinatal infections } \\
\text { Staphylococcal } \\
\text { peritonitis }\end{array}$ & Low serum L-ficolin & {$[60]$} \\
$\begin{array}{l}\text { Bacterial infections } \\
\text { following liver }\end{array}$ & $\begin{array}{c}(\text { FCN2-B }) \\
\text { transplantation }\end{array}$ & {$[65]$} \\
$\begin{array}{l}\text { Childhood infections } \\
\text { combined with allergic }\end{array}$ & Low serum L-ficolin & {$[62,70]$} \\
$\begin{array}{l}\text { diseases } \\
\text { Idiopathic } \\
\text { bronchiectasis }\end{array}$ & Low serum L-ficolin $)$ & {$[73,74]$} \\
$\begin{array}{l}\text { Preeclampsia } \\
\text { Chronic rheumatic heart }\end{array}$ & Promoter haplotype GGA & {$[68]$} \\
disease & Low serum L-ficolin & {$[63]$} \\
\hline
\end{tabular}

was slightly but significantly more frequent in patients with chronic rheumatic heart disease (CRHD) compared with healthy controls. Conversely, another haplotype was commoner in controls than in either CRHD or rheumatic fever patients. Since L-ficolin can readily bind to Streptococcus pyogenes and thereby activate complement [44], it is conceivable that these immunogenetic differences are related to an altered innate response.

A similar FCN2 investigation in Behcet's disease was essentially negative [80] as was the outcome of serum Lficolin measurements in sarcoidosis [81]. Nevertheless there was a trend towards lower circulating L-ficolin in sarcoid patients, in contrast to an increase noted for MBL.

Immunohistochemical evidence for L-ficolin involvement in IgA nephropathy has been found [82], but not in renal allograft rejection [83].

The clearest associations of L-ficolin insufficiency with disease susceptibility are summarised in Table 3.

\section{Animal Studies}

Animal work, though of indirect relevance to clinical situations, often provides valuable supplementary evidence concerning the function of human molecules. For example, native (plasma-derived) and recombinant porcine ficolin- $\alpha$ was found to neutralise porcine reproductive and respiratory virus (a major pathogen of swine) in vitro in a GlcNAcdependent manner [84]. However, variant alleles of ficolin$\alpha$ were not associated with common infectious diseases (pneumonia, enteritis, serositis, septicemia) at necropsy, despite significant associations with MBL-A, MBL-C, and surfactant protein A [85]. Of more tenuous significance was the finding that a chimeric molecule combining the lectin domain of MBL and the collagen-like region of L-ficolin had enhanced protective activity towards Ebola virus than either of the parent molecules [86].

Ficolin-A-deficient knockout mice have been established. Survival of these mice after infection with Streptococcus pneumoniae was reduced compared with that of wild-type mice [87], but the phenotype of the knockout mice has not been described in detail.

Human L-ficolin cDNA has been cloned into an expression plasmid and used in a murine model of Salmonella typhimurium infection [88]. Administration of L-ficolin in that form protected mice from a potentially lethal challenge with Salmonella, with bacterial counts dramatically reduced a week after infection compared with empty-vector-treated controls. The recombinant L-ficolin enhanced monocyte phagocytosis of Salmonella in a dose-dependent manner [88].

\section{Conclusions}

Human L-ficolin is a unique plasma recognition molecule with a broad specificity for microorganisms. It is capable of complementing collectins (such as MBL) and pentraxins in forming a battery of protective molecules constituting the first line of defence. Its functional activities are likely to be mediated through the lectin pathway of complement activation. Although clinical research involving L-ficolin is still in its infancy, evidence is emerging that insufficiency of L-ficolin might increase susceptibility to respiratory infections. In particular, the possibility that L-ficolin is a key factor in protection from Pseudomonas aeruginosa warrants further investigation.

\section{References}

[1] H. Ichijo, L. Ronnstrand, K. Miyagawa, H. Ohashi, C.H. Heldin, and K. Miyazono, "Purification of transforming growth factor- $\beta 1$ binding proteins from porcine uterus membranes," The Journal of Biological Chemistry, vol. 266, no. 33, pp. 22459-22464, 1991.

[2] M. Matsushita, Y. Endo, S. Taira et al., "A novel human serum lectin with collagen- and fibrinogen-like domains that functions as an opsonin," The Journal of Biological Chemistry, vol. 271, no. 5, pp. 2448-2454, 1996.

[3] Y. Le, S. M. Tan, S. H. Lee, O. L. Kon, and J. Lu, "Purification and binding properties of a human ficolin-like protein," Journal of Immunological Methods, vol. 204, no. 1, pp. 43-49, 1997.

[4] S. Harumiya, A. Omori, T. Sugiura, Y. Fukumoto, H. Tachikawa, and D. Fujimoto, "EBP-37, a new elastin-binding protein in human plasma: structural similarity to ficolins, transforming growth factor- $\beta 1$-binding proteins," Journal of Biochemistry, vol. 117, no. 5, pp. 1029-1035, 1995.

[5] P. F. Edgar, "Hucolin, a new corticosteroid-binding protein from human plasma with structural similarities to ficolins, transforming growth factor- $\beta 1$-binding proteins," FEBS Letters, vol. 375, no. 1-2, pp. 159-161, 1995.

[6] D. C. Kilpatrick, "Mannan-binding lectin: clinical significance and applications," Biochimica et Biophysica Acta, vol. 1572, no. 2-3, pp. 401-413, 2002.

[7] T. Ohashi and H. P. Erickson, "Two oligomeric forms of plasma ficolin have differential lectin activity," The Journal of Biological Chemistry, vol. 272, no. 22, pp. 14220-14226, 1997.

[8] A. S. Brooks, J. Hammermueller, J. P. DeLay, and M. A. Hayes, "Expression and secretion of ficolin $\beta$ by porcine neutrophils," Biochimica et Biophysica Acta, vol. 1624, no. 1-3, pp. 36-45, 2003. 
[9] Y. Fujimori, S. Harumiya, Y. Fukumoto et al., "Molecular cloning and characterization of mouse ficolin-a," Biochemical and Biophysical Research Communications, vol. 244, no. 3, pp. 796-800, 1998.

[10] T. Ohashi and H. P. Erickson, "Oligomeric structure and tissue distribution of ficolins from mouse, pig and human," Archives of Biochemistry and Biophysics, vol. 360, no. 2, pp. 223-232, 1998.

[11] Y. Kakinuma, Y. Endo, M. Takahashi et al., "Molecular cloning and characterization of novel ficolins from Xenopus laevis," Immunogenetics, vol. 55, no. 1, pp. 29-37, 2003.

[12] M. Matsushita, "The ficolin family: an overview," in CollagenRelated Lectins in Innate Immunity, D. Kilpatrick, Ed., pp. 1731, Research Signpost, 2007.

[13] P. Garred, C. Honoré, Y. J. Ma et al., "The genetics of ficolins," Journal of Innate Immunity, vol. 2, no. 1, pp. 3-16, 2009.

[14] R. Sugimoto, Y. Yae, M. Akaiwa et al., "Cloning and characterization of the Hakata antigen, a member of the ficolin/opsonin p35 lectin family," The Journal of Biological Chemistry, vol. 273, no. 33, pp. 20721-20727, 1998.

[15] T. Hummelshoj, L. M. Fog, H. O. Madsen, R. B. Sim, and P. Garred, "Comparative study of the human ficolins reveals unique features of Ficolin-3 (Hakata antigen)," Molecular Immunology, vol. 45, no. 6, pp. 1623-1632, 2008.

[16] H. Keshi, T. Sakomoto, T. Kawai et al., "Identificationand characterization of novel human collectin CL-K1," Microbiology and Immunology, vol. 50, pp. 1001-1013, 2006.

[17] S. Hansen, L. Selman, N. Palaniyar et al., "Collectin 11 (CL$11, \mathrm{CL}-\mathrm{K} 1$ ) is a MASP-1/3-associated plasma collectin with microbial-binding activity," Journal of Immunology, vol. 185, no. 10, pp. 6096-6104, 2010.

[18] Y. G. Ma, M. Y. Cho, M. Zhao et al., "Human mannosebinding lectin and L-ficolin function as specific pattern recognition proteins in the lectin activation pathway of complement," The Journal of Biological Chemistry, vol. 279, no. 24, pp. 25307-25312, 2004.

[19] V. Garlatti, N. Belloy, L. Martin et al., "Structural insights into the innate immune recognition specificities of $\mathrm{L}$ - and $\mathrm{H}$ ficolins," The EMBO Journal, vol. 26, no. 2, pp. 623-633, 2007.

[20] Y. Endo, Y. Sato, M. Matsushita, and T. Fujita, "Cloning and characterization of the human lectin P35 gene and its related gene," Genomics, vol. 36, no. 3, pp. 515-521, 1996.

[21] T. Hummelshoj, L. Munthe-Fog, H. O. Madsen, T. Fujita, M. Matsushita, and P. Garred, "Polymorphisms in the FCN2 gene determine serum variation and function of Ficolin-2," Human Molecular Genetics, vol. 14, no. 12, pp. 1651-1658, 2005.

[22] B. L. Herpers, M. M. Immink, B. A. W. De Jong, H. Van VelzenBlad, B. M. De Jongh, and E. J. Van Hannen, "Coding and non-coding polymorphisms in the lectin pathway activator L-ficolin gene in 188 Dutch blood bank donors," Molecular Immunology, vol. 43, no. 7, pp. 851-855, 2006.

[23] T. Hummelshøj, L. Munthe-Fog, H. O. Madsen, and P. Garred, "Functional SNPs in the human ficolin (FCN) genes reveal distinct geographical patterns," Molecular Immunology, vol. 45, no. 9, pp. 2508-2520, 2008.

[24] M. Cedzynski, L. Nuytinck, A. P. M. Atkinson et al., "Extremes of L-ficolin concentration in children with recurrent infections are associated with single nucleotide polymorphisms in the FCN2 gene," Clinical and Experimental Immunology, vol. 150, no. 1, pp. 99-104, 2007.

[25] L. Munthe-Fog, T. Hummelshøj, B. E. Hansen et al., "The impact of FCN2 polymorphisms and haplotypes on the Ficolin-2 serum levels," Scandinavian Journal of Immunology, vol. 65, no. 4, pp. 383-392, 2007.
[26] D. C. Kilpatrick, L. A. Mclintock, E. K. Allan et al., "No strong relationship between mannan binding lectin or plasma ficolins and chemotherapy-related infections," Clinical and Experimental Immunology, vol. 134, no. 2, pp. 279-284, 2003.

[27] A. S. Swierzko, A. Szala, M. Cedzynski et al., "Mannan-binding lectin genotypes and genotype-phenotype relationships in a large cohort of Polish neonates," Human Immunology, vol. 70, no. 1, pp. 68-72, 2009.

[28] S. L. MacDonald and D. C. Kilpatrick, "Collagen-related defence proteins as animal lectins," in Collagen-Related Lectins in Innate Immunity, D. Kilpatrick, Ed., pp. 1-16, Research Signpost, 2007.

[29] T. Hummelshoj, N. M. Thielens, H. O. Madsen, G. J. Arlaud, R. B. Sim, and P. Garred, "Molecular organization of human Ficolin-2," Molecular Immunology, vol. 44, no. 4, pp. 401-411, 2007.

[30] V. Garlatti, L. Martin, M. Lacroix et al., "Structural insights into the recognition properties of human ficolins," Journal of Innate Immunity, vol. 2, no. 1, pp. 17-23, 2009.

[31] M. Lacroix, C. Dumestre-Pérard, G. Schoehn et al., "Residue Lys57 in the collagen-like region of human L-ficolin and its counterpart Lys47 in H-ficolin play a key role in the interaction with the mannan-binding lectin-associated serine proteases and the collectin receptor calreticulin," Journal of Immunology, vol. 182, no. 1, pp. 456-465, 2009.

[32] D. C. Kilpatrick, "Isolation of human mannan binding lectin, serum amyloid P component and related factors from Cohn Fraction III," Transfusion Medicine, vol. 7, no. 4, pp. 289-294, 1997.

[33] A. Krarup, S. Thiel, A. Hansen, T. Fujita, and J. C. Jensenius, "L-ficolin is a pattern recognition molecule specific for acetyl groups," The Journal of Biological Chemistry, vol. 279, no. 46, pp. 47513-47519, 2004.

[34] A. Krarup, D. A. Mitchell, and R. B. Sim, "Recognition of acetylated oligosaccharides by human L-ficolin," Immunology Letters, vol. 118, no. 2, pp. 152-156, 2008.

[35] E. Gout, V. Garlatti, D. F. Smith et al., "Carbohydrate recognition properties of human ficolins: glycan array screening reveals the sialic acid binding specificity of M-ficolin," The Journal of Biological Chemistry, vol. 285, no. 9, pp. 6612-6622, 2010.

[36] N. J. Lynch, S. Roscher, T. Hartung et al., "L-ficolin specifically binds to lipoteichoic acid, a cell wall constituent of grampositive bacteria, and activates the lectin pathway of complement," Journal of Immunology, vol. 172, no. 2, pp. 1198-1202, 2004.

[37] J. Liu, M. A. M. Ali, Y. Shi et al., "Specifically binding of Lficolin to N-glycans of HCV envelope glycoproteins E1 and E2 leads to complement activation," Cellular and Molecular Immunology, vol. 6, no. 4, pp. 235-244, 2009.

[38] M. L. Jensen, C. Honoré, T. Hummelshøj, B. E. Hansen, H. O. Madsen, and P. Garred, "Ficolin-2 recognizes DNA and participates in the clearance of dying host cells," Molecular Immunology, vol. 44, no. 5, pp. 856-865, 2007.

[39] P. M. L. Ng, A. Le Saux, C. M. Lee et al., "C-reactive protein collaborates with plasma lectins to boost immune response against bacteria," The EMBO Journal, vol. 26, no. 14, pp. 34313440, 2007.

[40] Y. J. Ma, A. Doni, T. Hummelshøj et al., "Synergy between ficolin-2 and pentraxin 3 boosts innate immune recognition and complement deposition," The Journal of Biological Chemistry, vol. 284, no. 41, pp. 28263-28275, 2009.

[41] J. Lu and Y. Le, "Ficolins and the fibrinogen-like domain," Immunobiology, vol. 199, no. 2, pp. 190-199, 1998. 
[42] J. Zhang, J. Koh, J. Lu et al., "Local inflammation induces complement crosstalk which amplifies the antimicrobial response," PLoS Pathogens, vol. 5, no. 1, Article ID e1000282, 2009.

[43] A. Krarup, U. B. S. Sørensen, M. Matsushita, J. C. Jensenius, and S. Thiel, "Effect of capsulation of opportunistic pathogenic bacteria on binding of the pattern recognition molecules Mannan-binding lectin, L-ficolin, and H-ficolin," Infection and Immunity, vol. 73, no. 2, pp. 1052-1060, 2005.

[44] Y. Aoyagi, E. E. Adderson, C. E. Rubens et al., "Lficolin/mannose-binding lectin-associated serine protease complexes bind to group B streptococci primarily through $\mathrm{N}$ acetylneuraminic acid of capsular polysaccharide and activate the complement pathway," Infection and Immunity, vol. 76, no. 1, pp. 179-188, 2008.

[45] M. V. Carroll, N. Lack, E. Sim, A. Krarup, and R. B. Sim, "Multiple routes of complement activation by Mycobacterium bovis BCG," Molecular Immunology, vol. 46, no. 16, pp. 3367$3378,2009$.

[46] I. D. S. Cestari, A. Krarup, R. B. Sim, J. M. Inal, and M. I. Ramirez, "Role of early lectin pathway activation in the complement-mediated killing of Trypanosoma cruzi," Molecular Immunology, vol. 47, no. 2-3, pp. 426-437, 2009.

[47] I. Evans-Osses, E. A. Ansa-Addo, J. M. Inal, and M. I. Ramirez, "Involvement of lectin pathway activation in the complement killing of Giardia intestinalis," Biochemical and Biophysical Research Communications, vol. 395, no. 3, pp. 382-386, 2010.

[48] M. Matsushita, Y. Endo, and T. Fujita, "Cutting edge: complement-activating complex of ficolin and mannosebinding lectin-associated serine protease," Journal of Immunology, vol. 164, no. 5, pp. 2281-2284, 2000.

[49] J. S. Presanis, K. Hajela, G. Ambrus, P. Gál, and R. B. Sim, "Differential substrate and inhibitor profiles for human MASP-1 and MASP-2," Molecular Immunology, vol. 40, no. 13, pp. 921-929, 2004.

[50] A. Krarup, R. Wallis, J. S. Presanis, P. Gál, and R. B. Sim, "Simultaneous activation of complement and coagulation by MBL-associated serine protease 2," PLoS One, vol. 2, no. 7, article e623, 2007.

[51] A. Krarup, K. C. Gulla, P. Gál, K. Hajela, and R. B. Sim, “The action of MBL-associated serine protease 1 (MASP1) on factor XIII and fibrinogen," Biochimica et Biophysica Acta, vol. 1784, no. 9, pp. 1294-1300, 2008.

[52] K. C. Gulla, K. Gupta, A. Krarup et al., "Activation of mannanbinding lectin-associated serine proteases leads to generation of a fibrin clot," Immunology, vol. 129, no. 4, pp. 482-495, 2010.

[53] K. Takahashi, W. C. Chang, M. Takahashi et al., "Mannosebinding lectin and its associated proteases (MASPs) mediate coagulation and its deficiency is a risk factor in developing complications from infection, including disseminated intravascular coagulation," Immunobiology, vol. 216, no. 1-2, pp. 96-102, 2011.

[54] C. B. Chen and R. Wallis, "Two mechanisms for mannosebinding protein modulation of the activity of its associated serine proteases," The Journal of Biological Chemistry, vol. 279, no. 25, pp. 26058-26065, 2004.

[55] A. Kocsis, K. A. Kekési, R. Szász et al., "Selective inhibition of the lectin pathway of complement with phage display selected peptides against mannose-binding lectin-associated serine protease (MASP)-1 and-2: significant contribution of MASP-1 to lectin pathway activation," Journal of Immunology, vol. 185, no. 7, pp. 4169-4178, 2010.

[56] M. O. Skjoedt, Y. Palarasah, L. Munthe-Fog et al., "MBLassociated serine protease- 3 circulates in high serum concentrations predominantly in complex with Ficolin-3 and regulates Ficolin-3 mediated complement activation," Immunobiology, vol. 215, no. 11, pp. 921-931, 2010.

[57] M. Kuraya, Z. Ming, X. Liu, M. Matsushita, and T. Fujita, "Specific binding of L-ficolin and H-ficolin to apoptotic cells leads to complement activation," Immunobiology, vol. 209, no. 9, pp. 689-697, 2005.

[58] D. C. Kilpatrick, "Clinical significance of mannan binding lectin and L-ficolin," in Collagen-Related Lectins in Innate Immunity, D. C. Kilpatrick, Ed., pp. 57-84, Research Signpost, 2007.

[59] D. C. Kilpatrick, T. Fujita, and M. Matsushita, "P35, an opsonic lectin of the ficolin family, in human blood from neonates, normal adults, and recurrent miscarriage patients," Immunology Letters, vol. 67, no. 2, pp. 109-112, 1999.

[60] A. S. Swierzko, A. P. M. Atkinson, M. Cedzynski et al., "Two factors of the lectin pathway of complement, 1-ficolin and mannan-binding lectin, and their associations with prematurity, low birthweight and infections in a large cohort of Polish neonates," Molecular Immunology, vol. 46, no. 4, pp. 551-558, 2009.

[61] S. Sallenbach, S. Thiel, C. Aebi et al., "Serum concentrations of lectin-pathway components, children and in healthy neonates adults: mannan-binding lectin (MBL), M-, L-, and $\mathrm{H}$-ficolin, and MBL-associated serine protease-2 (MASP-2)," Pediatric Allergy and Immunology, vol. 22, no. 4, pp. 424-430, 2011.

[62] M. Cedzynski, A. P. M. Atkinson, A. S. Swierzko et al., "Lficolin (ficolin-2) insufficiency is associated with combined allergic and infectious respiratory disease in children," Molecular Immunology, vol. 47, no. 2-3, pp. 415-419, 2009.

[63] C. C. Wang, K. W. Yim, T. C. W. Poon et al., "Innate immune response by ficolin binding in apoptotic placenta is associated with the clinical syndrome of preeclampsia," Clinical Chemistry, vol. 53, no. 1, pp. 42-52, 2007.

[64] L. J. Schlapbach, M. Mattmann, S. Thiel et al., "Differential role of the lectin pathway of complement activation in susceptibility to neonatal sepsis," Clinical Infectious Diseases, vol. 51, no. 2, pp. 153-162, 2010.

[65] S. C.A. Meijvis, B. L. Herpers, H. Endeman et al., "Mannosebinding lectin (MBL2) and ficolin-2 (FCN2) polymorphisms in patients on peritoneal dialysis with staphylococcal peritonitis," Nephrology Dialysis Transplantation, vol. 26, no. 3, pp. 1042-1045, 2011.

[66] N. J. Klein and D. C. Kilpatrick, "Is there a role for mannan/mannose-binding lectin (MBL) in defence against infection following chemotherapy for cancer?" Clinical and Experimental Immunology, vol. 138, no. 2, pp. 202-204, 2004.

[67] D. C. Kilpatrick, "Mannan-binding lectin and stem cell transplantation," in Hematopoietic Stem Cell Transplantation Research Advances, K. B. Neuman, Ed., pp. 1-6, Nova Science, 2008.

[68] B. J. F. de Rooij, B. van Hoek, W. R. Ten Hove et al., "Lectin complement pathway gene profile of donor and recipient determine the risk of bacterial infections after orthotopic liver transplantation," Hepatology, vol. 52, no. 3, pp. 1100-1110, 2010.

[69] B.-J. F. de Rooij, M. T. van der Beek, B. van Hoek et al., "Combined donor-recipient mannose-binding lectin and ficolin-2 gene polymorphisms predispose to human cytomegalovirus infection after orthotopic liver transplantation," Journal of Hepatology, vol. 54, article S236, 2011.

[70] A. P. M. Atkinson, M. Cedzynski, J. Szemraj et al., "L-ficolin in children with recurrent respiratory infections," Clinical and Experimental Immunology, vol. 138, no. 3, pp. 517-520, 2004. 
[71] J. M. Ruskamp, M. O. Hoekstra, D. S. Postma et al., "Exploring the role of polymorphisms in ficolin genes in respiratory tract infections in children," Clinical and Experimental Immunology, vol. 155, no. 3, pp. 433-440, 2009.

[72] S. J. Chapman, F. O. Vannberg, C. C. Khor et al., "Functional polymorphisms in the FCN2 gene are not associated with invasive pneumococcal disease," Molecular Immunology, vol. 44, no. 12, pp. 3267-3270, 2007.

[73] D. C. Kilpatrick, J. D. Chalmers, S. L. MacDonald et al., "Stable bronchiectasis is associated with low serum L-ficolin concentrations," Clinical Respiratory Journal, vol. 3, no. 1, pp. 29-33, 2009.

[74] J. D. Chalmers, D. C. Kilpatrick, B. McHugh et al., "Single nucleotide polymorphisms in the ficolin-2 gene predispose to Pseudomonas aeruginosa infection and disease severity in noncystic fibrosis bronchiectasis," Thorax, vol. 66, supplement 4, pp. A1-A2, 2011.

[75] I. de Messias-Reason, P. G. Kremsner, and J. F. J. Kun, "Functional haplotypes that produce normal ficolin-2 levels protect against clinical leprosy," Journal of Infectious Diseases, vol. 199, no. 6, pp. 801-804, 2009.

[76] I. Faik, S. I. Oyedeji, Z. Idris et al., "Ficolin-2 levels and genetic polymorphisms of FCN2 in malaria," Human Immunology, vol. 72, no. 1, pp. 74-79, 2011.

[77] A. Assaf, I. Faik, T. Aebischer et al., "Genetic evidence of functional Ficolin-2 haplotype as susceptibility factor in cutaneous leishmaniasis," PloS One. In press.

[78] F. E. van de Geijn, A. Roos, Y. A. de Man et al., "Mannosebinding lectin levels during pregnancy: a longitudinal study," Human Reproduction, vol. 22, no. 2, pp. 362-371, 2007.

[79] I. J. Messias-Reason, M. D. Schafranski, P. G. Kremsner, and J. F. J. Kun, "Ficolin 2 (FCN2) functional polymorphisms and the risk of rheumatic fever and rheumatic heart disease," Clinical and Experimental Immunology, vol. 157, no. 3, pp. 395-399, 2009.

[80] X. Chen, Y. Katoh, K. Nakamura et al., "Single nucleotide polymorphisms of Ficolin 2 gene in Behçet's disease," Journal of Dermatological Science, vol. 43, no. 3, pp. 201-205, 2006.

[81] C. B. Svendsen, T. Hummelshøj, L. Munthe-Fog et al., "Ficolins and Mannose-Binding Lectin in Danish patients with sarcoidosis," Respiratory Medicine, vol. 102, no. 9, pp. 1237-1242, 2008.

[82] A. Roos, M. P. Rastaldi, N. Calvaresi et al., "Glomerular activation of the lectin pathway of complement in IgA nephropathy is associated with more severe renal disease," Journal of the American Society of Nephrology, vol. 17, no. 6, pp. 1724-1734, 2006.

[83] N. Imai, S. Nishi, B. Alchi et al., "Immunohistochemical evidence of activated lectin pathway in kidney allografts with peritubular capillary C4d deposition," Nephrology Dialysis Transplantation, vol. 21, no. 9, pp. 2589-2595, 2006.

[84] N. D. Keirstead, C. Lee, D. Yoo, A. S. Brooks, and M. A. Hayes, "Porcine plasma ficolin binds and reduces infectivity of porcine reproductive and respiratory syndrome virus (PRRSV) in vitro," Antiviral Research, vol. 77, no. 1, pp. 2838, 2008.

[85] N. D. Keirstead, M. A. Hayes, G. E. Vandervoort, A. S. Brooks, E. J. Squires, and B. N. Lillie, "Single nucleotide polymorphisms in collagenous lectins and other innate immune genes in pigs with common infectious diseases," Veterinary Immunology and Immunopathology, vol. 142, no. 1-2, pp. 113, 2011.

[86] I. C. Michelow, M. Dong, B. A. Mungall et al., "A novel L-ficolin/mannose-binding lectin chimeric molecule with enhanced activity against Ebola virus," The Journal of Biological Chemistry, vol. 285, no. 32, pp. 24729-24739, 2010.

[87] Y. Endo, M. Matsushita, and T. Fujita, "The role of ficolins in the lectin pathway of innate immunity," International Journal of Biochemistry and Cell Biology, vol. 43, no. 5, pp. 705-712, 2011.

[88] Y. Ma, F. Luo, T. Xiang et al., "Effects of L-ficolin on host resistance, gamma interferon production and phagocytosis against Salmonella infection," Molecular Immunology, vol. 44, p. 211, 2011. 

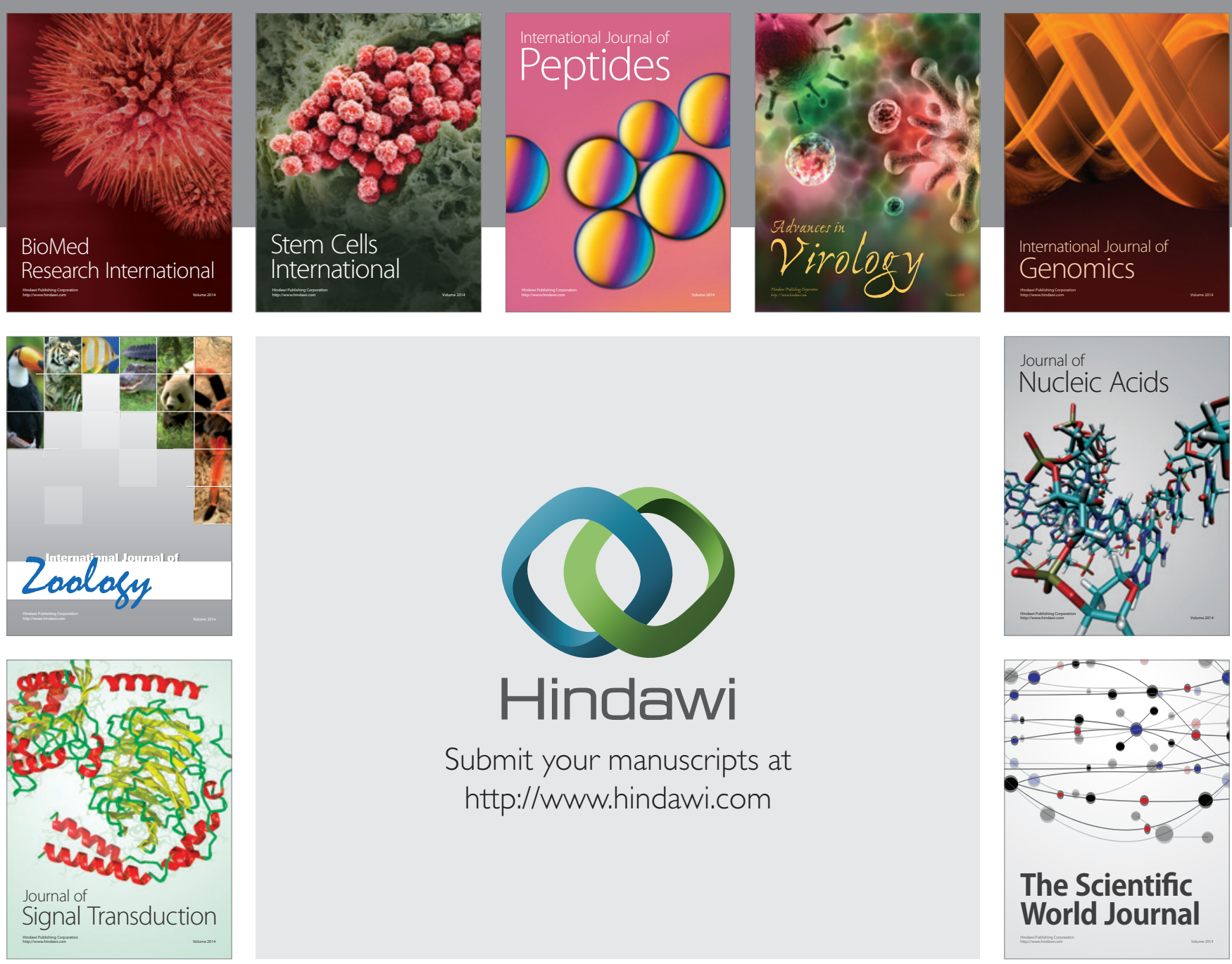

Submit your manuscripts at

http://www.hindawi.com
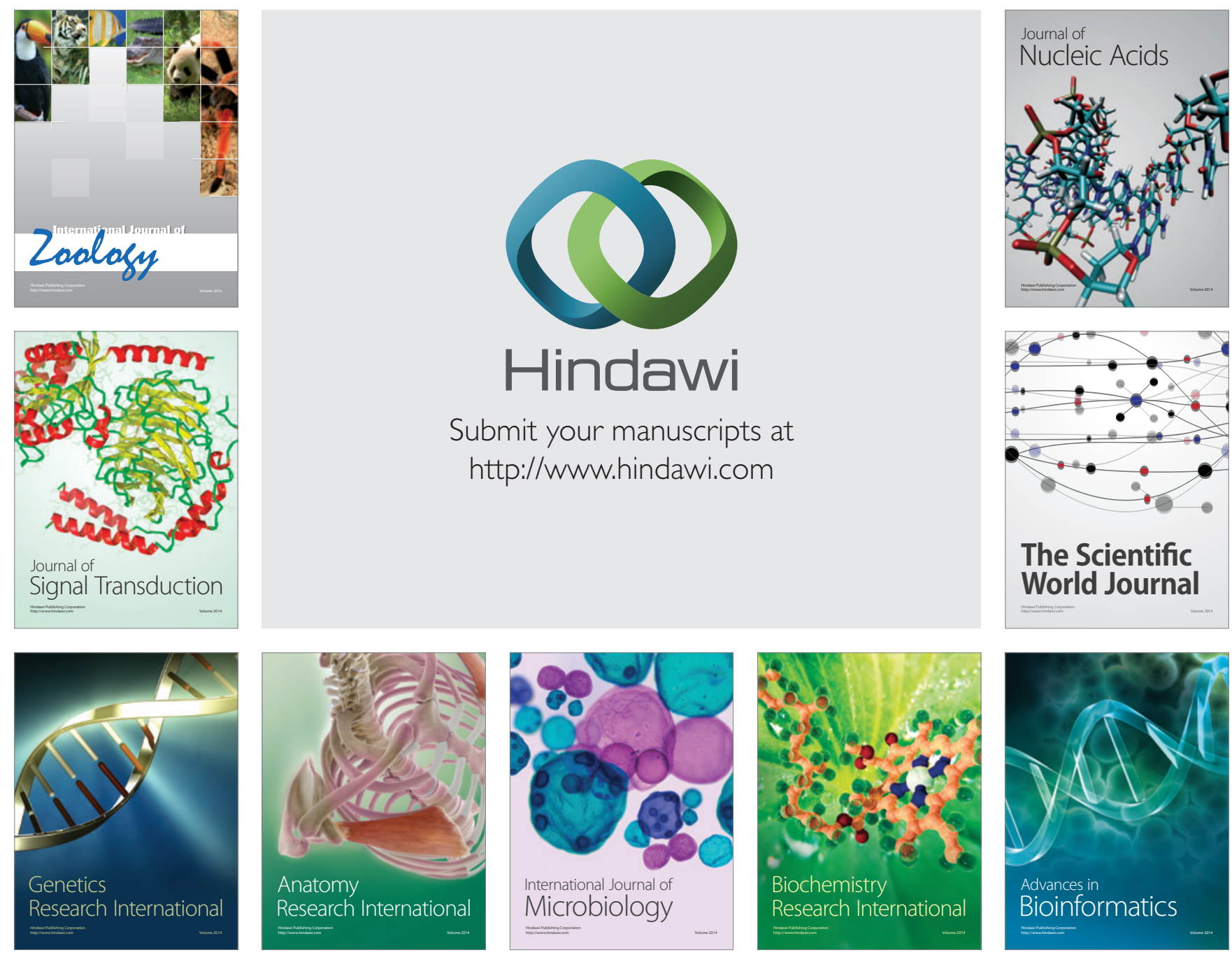

The Scientific World Journal
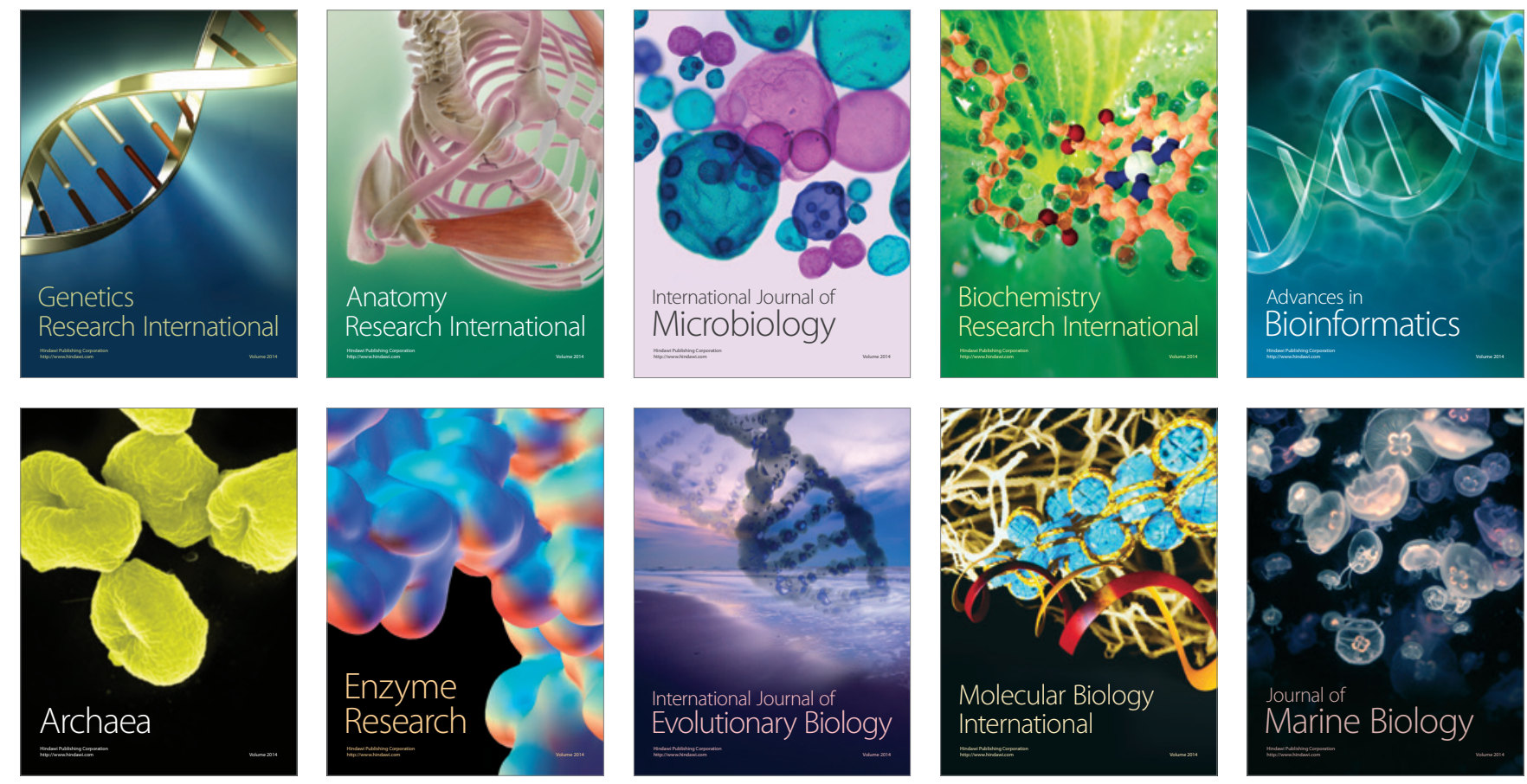